DOI: https://doi.org/10.30749/2594-8261.v4n1p34-44

\title{
A QUESTÃO DA MEMÓRIA NO ARQUIVO PESSOAL DE SANTOS DUMONT
}

\section{THE QUESTION OF MEMORY IN THE PERSONAL ARCHIVE OF SANTOS DUMONT}

Bárbara Cristina B. P. da Silva*

Resumo: O presente trabalho visa discutir as questões em torno da memória, tendo como base o Arquivo Pessoal de Santos Dumont. A intenção é trazer algumas discussões ocorridas em sala de aula, durante a disciplina Arquivo, Memória e Patrimônio, disciplina cursada no Programa de Pós-Graduação em Gestão de Documentos e Arquivos de tendo como base alguns dos textos lidos. O foco será discutir questões relacionadas à memória, a partir do acervo do pai da aviação.

Palavras-chave: Memória. Arquivo Pessoal. Santos Dumont.

Abstract: This paper aims to discuss the issues surrounding memory, based on the Personal Archive of Santos Dumont. The intention is to bring up some discussions that took place in the classroom, during the discipline Archive, Memory and Heritage, a course taken in the Post-Graduate Program in Management of Documents and Archives based on some of the texts read. The focus will be to discuss issues related to memory, based on the collection of the father of aviation.

Keywords: Memory. Personal archive. Santos Dumont.

\footnotetext{
* Mestre pelo Programa de Pós-Graduação em Gestão de Documentos e Arquivos da UNIRIO. Arquivista do Centro de Documentação da Aeronáutica (CENDOC). E-mail: bcbps@hotmail.com.
} 


\section{INTRODUÇÃO}

Durante o período em que esteve na França, mais precisamente no período de 1898 a 1904, Santos Dumont contratou os serviços de empresas especializadas em reunir matérias de jornais. As empresas contratadas estavam sediadas em três países: França, Estados e Inglaterra. ${ }^{1}$ Qualquer artigo, ilustração ou notícias de jornais de Paris, Nova lorque e Londres sobre assuntos aeronáuticos ou sobre a vida particular dele eram coletados e enviados ao brasileiro. Eram-lhe enviadas, principalmente pelo Courrier de La Presse. A maioria destas matérias continha notícias sobre as atividades do próprio Santos Dumont, principalmente nos anos de 1901 e 1902.

Dessa forma, diversos documentos foram reunidos. Não só os jornais, mas ainda algumas outras espécies documentais, como atas e cartas, por exemplo, e Santos Dumont trouxe a referida documentação para o Brasil, mais precisamente para sua residência em Petrópolis, a Encantada. Este arquivo permaneceu lá até o seu falecimento. Ao eclodir a Revolução Constitucionalista de 1932, a parte da família que residia em São Paulo, cidade que foi mais duramente atingida, receou uma invasão e extravio dos pertences pessoais que se encontravam na casa de Petrópolis, pois ela ficava desguarnecida de segurança. O Sr. Jorge Toledo Dodsworth, casado com a sobrinha de Santos Dumont, Sophia Dumont, e pai de Sophia Helena², preocupado, trouxe os referidos pertences, e dentre eles, um baú de vime fechado com os "papéis" de Santos Dumont, que foi depositado no porão da sua residência no Flamengo - RJ, e lá permaneceu por mais de 30 anos.

\section{DESENVOLVIMENTO}

Para darmos início a discussão, apresentaremos o acervo e como este fora organizado, constituindo a história do arquivo ou a trajetória da gestão física e do movimento dos documentos ao longo do tempo, pois, de acordo com Millar.

\footnotetext{
${ }^{1}$ É interessante destacar que cada um desses países trata Santos Dumont de forma distinta. E mesmo que houvesse algum deboche publicado sobre ele, este não foi desconsiderado e reunido por ele.

${ }^{2}$ Aqui destacamos a Senhora Sophia Helena pelo fato de ser a doadora do Acervo ao Centro de Documentação da Aeronáutica (CENDOC).
} 
A história dos arquivos, talvez mais precisamente denominada de proveniência, seria a história dos próprios documentos: como foram criados e utilizados; quem tinha a sua posse e quando; para onde foram deslocados e por que; se algum documento foi perdido e ou transferido, aprimorado e alterado, incluindo o motivo, e o tempo em que foram recolhidos à custódia. (MILLAR, 2015, p. 14).

Com o falecimento do Senhor Jorge Toledo Dodsworth, sua viúva resolveu desfazer-se da residência. Nesta ocasião, em 1969, o baú foi reencontrado e deixado por Sophia sob a guarda do Tenente Brigadeiro Lavenère-Wanderley, casado com a filha do Sr. Jorge Toledo, Sra. Sophia Helena.

\begin{abstract}
"Após o falecimento do meu avô, minha avó começou a desmontar a casa. Pediu então a meu pai que fosse ao porão ver um cesto de vime que continha, segundo ela, uma série de papéis antigos. Era para ele ver o que prestava e jogar fora o que não prestasse", conta Alberto Dodsworth Wanderley, filho do brigadeiro e de Sophia Helena e sobrinho-bisneto de Santos-Dumont. "Quando meu pai viu que aquilo não era papel velho, que ali havia recortes de jornal do mundo inteiro com notícias relacionadas a Santos-Dumont, ele disse à minha avó que ia recolher tudo. Como historiador que era, reconheceu aquele material como documentos históricos e se interessou em fazer ele mesmo sua classificação." (GARBIN, 2015).
\end{abstract}

Ainda de acordo com depoimento do Sr. Alberto, seu pai, separou e limpou o material e passou a organizá-lo em ordem cronológica, dividido por assuntos. "Depois meu pai encadernou todo esse acervo e botou à disposição de pesquisadores." (GARBIN, 2015). Entusiasta dos feitos de Santos-Dumont, o Tenente Brigadeiro Lavenère-Wanderley deixou em páginas datilografas detalhes de seu trabalho de coleta, organização e manutenção do acervo: "Nos três anos que se seguiram, fiz a limpeza, a recuperação, nova colagem dos recortes de jornais nas respectivas etiquetas e a sua arrumação por ordem cronológica e por assuntos", escreveu o Tenente Brigadeiro, conforme registro em documento datilografado, disponível na coleção Santos Dumont. ${ }^{3}$

\begin{abstract}
A coleção de recortes de jornais que se achavam na casa $A$ Encantada, em Petrópolis, depois do falecimento de Santos Dumont, abrange os anos de 1899 a 1903, isto é, o período em que Santos Dumont se dedicava aos seus balões. A referida coleção não cobre o período em que o grande inventor brasileiro estava dedicado à resolução do problema do voo do mais pesado que o ar (LAVANÈRE-WANDERLEY, 1975).
\end{abstract}

\footnotetext{
${ }^{3}$ O Centro de Documentação da Aeronáutica também recebeu uma coleção de Santos Dumont, com documentos reunidos após o seu falecimento.
} 
No total, o Tenente Brigadeiro Lavenère-Wanderley encontrou nas malas esquecidas no casarão do Flamengo 133 recortes de jornal de 1899, 203 de 1900, 7.689 de 1901, 3.995 de 1902 e 608 de 1903, perfazendo um total de 12.628 documentos. O aumento da quantidade em 1901 e 1902 se explica pela sequência de feitos de Santos-Dumont, no período que, segundo o referido Oficial General é o "mais glorioso de sua carreira, quando a população de Paris, da França e de todo o mundo civilizado acompanhava, empolgada, as suas sensacionais experiências sobre a dirigibilidade dos balões". (GARBIN, 2015).

O Tenente Brigadeiro, nos três anos subsequentes, cuidou dos documentos, organizando-os em cinco volumes encadernados que juntos possuem em torno de 2200 unidades documentais ${ }^{4}$, as quais perfazem testemunhos da trajetória de Santos Dumont durante os anos de 1899 a 1903. Os registros posteriores a essa data foram conseguidos e reunidos pelo Tenente Brigadeiro Lavenère-Wanderley, enriquecendo o acervo.

Já a seleção da documentação preservada nos arquivos pessoais é evidentemente marcada pela subjetividade de seus produtores, afetada ainda, em boa parte dos casos, pela intencionalidade desses - e de todos que manipularam a documentação antes de sua organização arquivística. Por meio de tais documentos, os produtores promovem a construção de uma memória "desejada", garantindo assim a transferência à posteridade de determinados fatos ou visões legitimados por essa documentação. (ABELLÁS, 2012, p. 76).

É interessante destacar que não foram retiradas espécies documentais do acervo, mesmo sendo constituídos por conteúdos que poderiam ser encarados com tons irônicos, a exemplo de matérias jornalísticas da imprensa norte-americana. Dessa maneira, infere-se que a família do inventor brasileiro quis preservar seu desejo de constituir uma memória fidedigna à realidade de formação de sua própria memória, para sua disseminação posterior.

Destaca-se a importância da realização de entrevistas com os possíveis doadores de acervos, quando possível, as quais devem preceder a doação em si, para que $o$ arquivista obtenha subsídios para planejar adequadamente o processamento técnico-arquivístico a ser executado. Sempre haverá informações relevantes a serem apresentadas e destacadas que poderão preencher lacunas outrora existentes. A

\footnotetext{
${ }^{4}$ Não há qualquer detalhamento por parte da família do que foi feito com o restante da documentação. Provavelmente documentos danificados pelo tempo, conforme será visto a seguir, foram retirados.
} 
operação técnica-arquivística do Acervo de Santos Dumont iniciou sem fundamentos básicos que deveriam precedê-la, pois, pelo fato de o arquivo estar inerte há 10 anos na Instituição a que foi confiada, inexistiam detalhes prévios acerca do acervo. Nesse viés, foram utilizados conhecimentos provenientes da biografia do produtor, dos documentos do Projeto Santos Dumont e de artigos publicados sobre o produtor em apreço. Porém, com a realização da entrevista do Sr. Alberto Dodsworth, ao Jornal O Estadão, em 2015, pode-se verificar que a grande maioria dos documentos foi retirada do acervo, visto que o Tenente Brigadeiro contabilizou os documentos por período e verificou que no baú de vime havia em torno de mais de 10.000 unidades documentais. Porém, conforme lido no parágrafo anterior, nos cinco álbuns montados pelo Tenente Brigadeiro, encontrou-se pouco mais de 2.000 documentos, e mais um álbum, chamado de avulsos. "Contudo, essa organização acabou por criar um conjunto de documentos avulsos que não utilizados nos álbuns: No total, os documentos considerados avulsos são em torno de 1473 unidades." (SOUZA, 2012, p. 51).

O sexto volume, chamado de avulsos, nada tinha de especial, apesar de a família ter solicitado, no Termo de Doação, um tratamento especial ao mesmo. A análise dos avulsos conotou que os mesmos não foram utilizados, por haver matérias e/ou fotografias muito similares as contempladas nos cinco volumes. Não haveria por que não as utilizar. O Tenente Brigadeiro fez uma seleção no acervo, e determinou quais recortes de jornal fariam parte ou não. No Termo de Doação consta uma cláusula que caracterizaria esse álbum como especiais, pois foi o único álbum que a família pediu ao Centro de Documentação da Aeronáutica - CENDOC, instituição para qual foi doado o Acervo, em 2004, uma relação completa de todos os itens documentais e que, ainda conforme o Termo, caso algum familiar julgasse necessário, retirariam documentos e estes não mais fariam parte do acervo doado. É importante "tratar o arquivo pessoal como conjunto indissociável, cujas parcelas só têm sentido se consideradas em suas mútuas articulações e quando se reconhecem seus nexos com as atividades e funções de que se originaram." (CAMARGO; GOULART, 2007, p. 35-36).

Importante destacar que, até o momento em que o Brigadeiro recebeu o Acervo, este não havia recebido qualquer tipo de organização. Mesmo após a entrevista com o Senhor Alberto ficou constatado que os documentos foram simplesmente depositados no baú de vime, por Santos Dumont, sem qualquer 
tratamento.

Outro ponto a ser exaltado trata da interferência familiar no fundo 5 . Ao realizar este exame da proveniência, verifica-se que a família interferiu na composição do fundo de duas maneiras: Uma ${ }^{6}$ porque incorporaram ao fundo original uma parcela de arquivo, porém esta não supriu a outra interferência, realizada pelo Brigadeiro, com a retirada de documentos que poderiam, por exemplo, constranger o produtor. De acordo com Heymann (1997, p. 45) pensando-se na categoria do produtor, "Após sua morte, ocorre a interferência de familiares, que geralmente reduzem o universo acumulado segundo uma avaliação baseada em novas diretrizes e interesses." Não havia, até então, qualquer registro claro desta interferência, sabida graças a entrevista ao Jornal O Estadão pelo Senhor Alberto e ao tratamento dado ao acervo.

O Tenente Brigadeiro encontrou o velho baú em péssimas condições e, como lembrava Sra. Sophia Helena, naquela época não existia, ainda, o Aterro do Flamengo e o mar ficava a poucos metros da casa, invadindo o porão, por algumas ocasiões. $O$ baú se desmanchou ao ser aberto e os jornais estavam bastante úmidos, tanto que alguns jornais se perderam definitivamente. $O$ trabalho do Brigadeiro foi de grande determinação: separava os jornais por lotes para recuperá-los. Em seguida, procedeu à organização, recortando cada artigo e colocando o cabeçalho apropriado, mantendo as referências do jornal de origem e permitindo a identificação completa de cada fonte.

$\mathrm{O}$ arquivo de Santos Dumont é formado por documentos retidos a partir de buscas junto à família de Santos Dumont e às pessoas que, possivelmente, mantinham algum documento, sobre especificidades das posses do inventor, por exemplo, o que pode ser comprovado por intermédio das cartas escritas pelo Brigadeiro aos amigos e familiares, e também na realização de um Concurso patrocinado por uma famosa empresa de reprografia para auxiliar o Brigadeiro na localização de outros documentos sobre Santos Dumont.

\begin{abstract}
Assim, a intencionalidade é, em boa parte dos casos, o critério principal para guarda e descarte de documentos, desenhando o arquivo segundo a visão particular de seu produtor e / ou daqueles que tiveram tal documentação sob seus cuidados. E é essa manipulação inicial, plena em valores subjetivos, em grande parte a responsável por estabelecer o que "merece" ser lembrado e o que "pode" - ou "deve" ser esquecido, em uma pré-seleção documental que foge ao controle do arquivista e de seus métodos. (ABELLÁS, 2012, p. 76).
\end{abstract}

\footnotetext{
${ }^{5} \mathrm{O}$ referido parágrafo trata das primeiras das interferências familiares no arquivo pessoal.

${ }^{6}$ Importante destacar que houve sim uma interferência positiva, pois caso esta não ocorresse, não encontraríamos no acervo documentos da data de seu nascimento até a data de seu falecimento.
} 
O arquivo pessoal de Santos Dumont é, primordialmente, um conjunto de fontes relevantes para a história e o desenvolvimento científico nacional. Essa consciência permeou personalidades chaves para sua manutenção até os nossos dias: Senhor Jorge Toledo Dodsworth, o Tenente Brigadeiro Lavenère-Wanderley, a Senhora Sophia Helena e a Senhora Sophia Helena Dodsworth Wanderley. Todos vinculados à história de Santos Dumont por laços familiares cumpriram com carinho, com extrema reverência e muita dignidade a tarefa de conservar os papéis. Porém, uma qualidade foi fundamental à família de Santos Dumont: a tenacidade com a qual lutaram para não deixar o tempo esmaecer os papéis e a memória. Tenacidade que era própria de Santos Dumont ${ }^{7}$.

Para começarmos a nossa discussão sobre memória, tomando como base o Arquivo Pessoal de Santos Dumont, a partir do que se discorreu sobre o acervo, vamos introduzir uma definição para temática, a qual foi apresentada por Le Goff, que diz que a memória é a propriedade de conservar certas informações (LE GOFF, 1990, p. 366). Logo no início da apresentação do acervo, já se tem uma noção da documentação reunida por Santos Dumont. Quando Santos Dumont começou com suas criações e seus testes, este solicitou os clippings a empresas em três países. $O$ que queria Santos Dumont, ao solicitar os clippings? O que leva um homem a solicitar os serviços de clipping a uma empresa? Ousadia? Ego? Necessidade de reconhecimento? Auto afirmação? Talvez um pouco de tudo, mas o principal, Santos Dumont era um homem a frente de seu tempo. Toda notícia que saia sobre o inventor era recortada...toda notícia mesmo, inclusive fofocas! Santos Dumont iniciou seu acervo pessoal com notícias e fotos sobre si e daí desencadeou uma avalanche de informações. O mais interessante é, ao analisar cada jornal, por diferentes países, vêse a idolatria francesa a Santos Dumont e o deboche dos americanos. Mas Santos Dumont, em nenhum momento, deixa de defender suas raízes e seus inventos, mostrando-se firme e decidido a ir em frente, até o fim$^{8}$.

Resumindo", conclui Perec,"eu me arrumo como posso."Z Passamos assim o tempo a arquivar nossas vidas: arrumamos, desarrumamos, reclassificamos. Por meio dessas práticas minúsculas, construímos uma imagem, para nós mesmos e às vezes para os outros. Analisar esse "arrumar-

\footnotetext{
${ }^{7}$ Extrato de foro íntimo retirado da página do CENDOC, texto que fora escrito por alguns militares da Organização Militar (OM).

${ }^{8}$ Opinião da autora, após a análise do acervo de Santos Dumont.
} 
se" é "interrogar o que parece ter deixado para sempre de nos espantar (ARTIÈRES, 2001, p. 10).

Diante do exposto, vê-se que Santos Dumont queria comprovar as realizações que teve na época e todos os seus feitos e conquistas. Seria uma espécie de auto afirmação visto que, durante o período citado, muitas corridas aéreas estavam ocorrendo. Além disso, percebe-se que Santos Dumont, independentemente do julgamento que tivera sido feito a seu respeito, pensou em, literalmente, construir uma imagem de si próprio, com toda e qualquer opinião sobre ele ali reunida.

O estudo da vida de Santos-Dumont no período de 1899 a 1904, tendo como fonte uma ampla amostra iconográfica, afirma-se como uma rica oportunidade de compreender os diversos elementos que fundamentaram leituras posteriores. As várias formas de se capturar todo o processo de construção e desenvolvimento dos dirigíveis apresentam os pontos fundamentais da imagem de Santos-Dumont perante a sociedade da época. (SOUZA, 2012, p. 54-55).

Analisando os artigos de jornal colecionados pelo inventor, destacam-se os posicionamentos contrários das imprensas francesa e americana. Nos jornais franceses, percebe-se o quanto o aeronauta era aclamado e elogiado. Santos Dumont era destacado como esportista e balonista, o qual apresentava algo diferente e que poderia solucionar a questão da dirigibilidade. Percebe-se ainda que, mesmo com as charges que saiam a seu respeito, estas não tinham cunho satírico. Julga-se, portanto, que Santos Dumont decidiu por guardar esses recortes pelo fato de a imprensa francesa tanto o enaltecer, talvez por este ter a nacionalidade francesa também.

Já a imprensa americana tratava de maneira debochada a trajetória do inventor brasileiro. Parecia ainda, que os jornais americanos desejavam afastar Santos Dumont do público, visto que as notícias que eram publicadas tinham o costume desmentir afirmações feitas pelo aeronauta. As caricaturas americanas foram as mais críticas e desconstruíram por completo a imagem de Santos Dumont. Mais se criticou Santos Dumont do que se destacou sua conquista. Se Santos Dumont julgasse os artigos americanos como julgamos os recortes franceses anteriormente, estes não estariam no acervo.

Isto que se entende ser o mais interessante no acervo: Santos Dumont, ao preservar todos estes artigos, independentemente do que a imprensa noticiou a respeito de suas criações ou as desconstruções dele próprio, preservou um panorama 
geral de como era visto mundialmente ${ }^{9}$. E é interessante perceber como uma mesma pessoa é vista por diferentes vieses.

Mesmo em sua forma histórica mais séria e legítima, a memória do Holocausto se estrutura de modo bem diferente no país das vítimas e no país dos perpetuadores, e também diverso nos países da aliança ante nazista. (HUYSSEN, 2000, p. 80).

Este extrato do texto de Huyssen representa exatamente o que aconteceu com Santos Dumont àquela época: o mesmo homem visto de maneira distinta por dois países, assim como a recordação do Holocausto para países distintos tem significados distintos. Este texto relacionou-se muito bem com que se pretende apresentar sobre memória concernente ao acervo de Santos Dumont, pois essas diferenças justamente são as formadoras do que hoje conhecemos como a história de Santos Dumont. Com isso preservado, podemos ter um conhecimento completo de como ele era visto, conhecido e reconhecido.

Essa fratura multiplada memória do Holocausto em diferentes países e a sedimentação em diversas camadas de imagens e discursos que variam desde o documentário até a telenovela, ... contra congelamento da memória numa imagem traumática ou no enfoque embotador dos números. (HUYSSEN, 2000, p. 81-82).

Dando continuidade à análise do Arquivo Pessoal de Santos Dumont, percebeu-se que a família, mais especificamente o marido da sobrinha neta de Santos Dumont, prosseguiu a ação anterior ao do pai da aviação, com a guarda de recortes de jornal sobre o inventor. Curiosamente, o Tenente Brigadeiro manteve em seu próprio arquivo pessoal documentos de todos os gêneros e espécies possíveis, através dos quais ele pôde contar a História da FAB, e com a vida de Santos Dumont ele fez o mesmo: Montou álbuns que, organizados tematicamente, contavam a trajetória de Santos Dumont.

Por "tradição inventada" entende-se um conjunto de práticas, normalmente reguladas por regras tácita ou abertamente aceitas; tais práticas, de natureza ritual ou simbólica, visam inculcar certos valores e normas de comportamento através da repetição, o que implica, automaticamente; uma continuidade em relação ao passado. (HOBSBAWM, 1984, p. 9).

\footnotetext{
${ }^{9}$ Apesar de a autora tratar especificamente de dois continentes, usou-se o termo mundialmente por ter encontrado no Acervo, durante o tratamento técnico, documentos em inúmeros idiomas e de toda a parte do mundo.
} 
A partir das leituras sobre tradições e analisando os feitos da família, em relação ao Acervo, pode-se considerar que a ação de colecionar artigos de jornal é uma prática que foi perpetuada na família e pela família, algo feito até os dias atuais. Julga-se que a família deu continuidade a ação primeira de Santos Dumont com a ideia de manter viva a memória do inventor, de pai da aviação, inclusive para justificar os seus feitos sobre os dos Irmãos Wrigthe.

\section{CONCLUSÃO}

Desde a reunião dos documentos, a organização dada pelo Tenente Brigadeiro Lavenère-Wanderley, até a doação do acervo ao CENDOC, percebe-se que a intenção, não só do inventor quanto a de sua família, conforme o próprio termo de doação previa, era que toda e qualquer pessoa pudesse conhecer Santos Dumont e, sempre que possível, pudesse perpetuar sua memória, e que o povo brasileiro pudesse jamais esquecê-lo. De acordo com Santos (2002, p. 141), a "amnésia coletiva" nada mais é do que o esquecimento de determinados aspectos para que outros sobrevivam. Talvez, para a família principalmente, já seja mais do que a hora de resgatar e fazer com que Santos Dumont sobreviva, em meio ao esquecimento frequente de sua existência, importante e com destaque no cenário mundial, um verdadeiro herói da nação brasileira.

\section{REFERÊNCIAS}

ABELLÁS, José Benito Yárritu. Arquivos pessoais, saberes coletivos: a organização da documentação pessoal e pública de cientistas - o caso Hussak. In: SILVA, Maria Celina Soares de Mello; SANTOS, Paulo Roberto Elian dos. (org.). Arquivos pessoais: história, preservação e memória da ciência. Rio de Janeiro: Associação dos Arquivistas Brasileiros, 2012. p. 75-88.

ARTIÈRES, Philippe. Arquivar a própria vida. Revista Estudos Históricos, Rio de Janeiro, v. 11, n. 21, p. 9-34, 1998. Disponível em:

http://bibliotecadigital.fgv.br/ojs/index.php/reh/article/view/2061. Acesso em: 30 maio 2017.

CAMARGO, Ana; GOULART, Silvana. Tempo e circunstância: a abordagem contextual dos arquivos pessoais. São Paulo: IFHC, 2007.

SOUZA, Renato Vilela Oliveira de. Santos Dumont e as caricaturas: uma história 
cultural da aviação. In: SILVA, Maria Celina Soares de Mello; SANTOS, Paulo Roberto Elian dos. (org.). Arquivos pessoais: história, preservação e memória da ciência. Rio de Janeiro: Associação dos Arquivistas Brasileiros, 2012. p. 51-74.

GARBIN, Luciana. Especial Santos-Dumont. Estadão, [S. I.], 2015. Disponível em: http://infograficos.estadao.com.br/especiais/a-redescoberta-de-santos-dumont. Acesso em: 30 maio 2017.

HEYMANN, Luciana Quillet. Indivíduo, memória e resíduo histórico: uma reflexão sobre arquivos pessoais e o caso Filinto Müller. Revista Estudos Históricos, Rio de Janeiro, v. 10, n. 19, p. 41-66, 1997.

HOBSBAWN, Eric; RANGER, Terence. Introdução. In: HOBSBAWN, Eric; RANGER, Terence. A invenção das tradições. Tradução: Celina Cardim Cavalcante. Rio de Janeiro: Paz e Terra, 1984. p. 9-23.

HUYSSEN, Andreas. Monumentos e memórias do Holocausto numa idade da mídia. In: HUYSSEN, Andreas. Seduzidos pela memória: arquitetura, monumentos, mídia. Rio de Janeiro: Aeroplano, 2000. p. 67-88.

LAVANÈRE-WANDERLEY, Nélson Freire. História da Força Aérea Brasileira. Rio de Janeiro: Gráfica Brasileira, 1975.

LE GOFF, Jacques. Documento/monumento. In: LE GOFF, Jacques. História e memória. Campinas, SP: Ed. Unicamp, 1990.

MILLAR, Laura Agnes. A morte dos fundos e a ressurreição da proveniência: o contexto arquivístico no epaço e no tempo. Informação Arquivística, Rio de Janeiro, v. 4, n. 1, p. 144-162, 2015.

SANTOS, Myrian Sepúlveda dos. O pesadelo da amnésia coletiva: um estudo sobre os conceitos de memória, tradição e traços do passado. Cadernos de

Sociomuseologia, [S. I.], v. 19, n. 19, p. 139-171, 2002.

Recebido em 27/10/2019.

Aceito em 05/05/2020. 